\title{
Baroreflex control of sympathetic activity in experimental hypertension
}

M.C.C. Irigoyen ${ }^{1,2}$ and E.M. Krieger ${ }^{2}$

\section{Correspondence \\ E.M. Krieger \\ Unidade de Hipertensão \\ InCor, HCFMUSP \\ Av. Enéas C. Aguiar, 44 \\ 05403-000 São Paulo, SP \\ Brasil \\ Fax: 55 (011) 3069-5048 \\ E-mail: \\ edkrieger@ incor4.incor.usp.br \\ Presented at the II International Symposium on Vasoactive Peptides, O uro Preto, MG, Brasil, \\ October 6-8, 1997.}

Research supported by FINEP, FAPERGS, FAPESP and FEJZ.

Received April 6, 1998

Accepted April 22, 1998

\author{
1Departamento de Fisiologia, Instituto de Ciências Básicas da Saúde, U niversidade \\ Federal do Rio Grande do Sul, Porto Alegre, RS, Brasil \\ 2Unidade de Hipertensão, Instituto do Coração, Hospital das Clínicas, Faculdade de \\ Medicina, Universidade de São Paulo, São Paulo, SP, Brasil
}

\section{Abstract}

The arterial baroreceptor reflex system is one of the most powerful and rapidly acting mechanisms for controlling arterial pressure. The purpose of the present review is to discuss data relating sympathetic activity to the baroreflex control of arterial pressure in two different experimental models: neurogenic hypertension by sinoaortic denervation (SAD) and high-renin hypertension by total aortic ligation between the renal arteries in the rat. SAD depresses baroreflex regulation of renal sympathetic activity in both the acute and chronic phases. However, increased sympathetic activity (100\%) was found only in the acute phase of sinoaortic denervation. In the chronic phase of SAD average discharge normalized but the pattern of discharges was different from that found in controls. High-renin hypertensive rats showed overactivity of the renin angiotensin system and a great depression of the baroreflexes, comparable to the depression observed in chronic sinoaortic denervated rats. However, there were no differences in the average tonic sympathetic activity or changes in the pattern of discharges in high-renin rats. We suggest that the difference in the pattern of discharges may contribute to the increase in arterial pressure lability observed in chronic sinoaortic denervated rats.

\section{Introduction}

The arterial baroreceptor reflex system is one of the most powerful and rapidly acting mechanisms for controlling arterial pressure (AP). The rapid resetting of arterial baroreceptor afferents toward any sustained new level of blood pressure ensures that the reflex acts as an effective buffer of the shortterm blood pressure fluctuations that accompany daily life (1). In fact, the minimization of blood pressure variability by baroreflex mechanisms is important since studies suggest that a reduced baroreflex is an independent risk factor for sudden death after myocardial infarction $(2,3)$. Studies performed in experimental animals and in humans have documented that high blood pressure markedly impairs baroreceptor control of heart rate (HR) (4). If a similar impairment also occurs in baroreceptor control of sympathetic activity modulating peripheral vasomotor tone is not well known. However, there is evidence in human essential hyper- 
tension and in spontaneously hypertensive rats (SHRs) suggesting a selective overactivity of sympathetic tone to the heart and kidney (5). In the last years we have been analyzing the complex relationship between baroreceptor function and heart rate and renal sympathetic nerve activity (RSNA) control in experimental hypertension. The purpose of the present review is to provide evidence concerning the role of the autonomic nervous system in arterial pressure control in two different models: neurogenic hypertension produced by sinoaortic denervation and high-renin hypertension produced by total aortic ligation between the renal arteries.

\section{The baroreceptor reflex}

The components of the reflex arc responsible for the short-term blood pressure regulation are: 1) receptor endings of afferent fibers located in the adventitia of the carotid sinus and aortic arch and running along branches of the glosso-pharyngeal and vagus nerves, respectively; 2) central integrative sites, represented by the nucleus tractus solitarii (dorsal medulla), caudal ventrolateral medulla and rostral ventrolateral medulla; 3) efferent fibers to the intermediolateral cell column (sympathetic preganglionic neurons), the source of sympathetic outflow to the periphery and efferent fibers to preganglionic parasympathetic neurons; 4) the target organs of these efferent fibers, i.e., the heart and the vascular tree.

As universally accepted, the arterial baroreceptors are the major components maintaining moment-to-moment reflex control of both sympathetic and vagal innervation to the cardiovascular system (for reviews, see 6-8).

\section{The role of the baroreflex in the short-term control of blood pressure}

The primary purpose of the arterial baroreflex is to provide rapid and efficient stabilization of arterial blood pressure on a beat-to-beat basis by means of carotid and aortic baroreceptors. Impaired baroreflexes lead to increased blood pressure variability (5). However, over the longer term ( $24 \mathrm{~h}$ ), no significant relationship between baroreflex sensitivity and variability of blood pressure was found (9). The role of the baroreflex in the long-term control of blood pressure is characterized by the ability of arterial baroreceptors to reset toward any sustained new level of blood pressure in hypotension or hypertension (10). The resetting to high levels of pressure may be acute or chronic (11). Acute resetting does not change baroreflex sensitivity (12). Nevertheless, chronic and complete resetting leads to an impairment (30\%) of baroreflex sensitivity $48 \mathrm{~h}$ after hypertension. The impairment observed 2 days after hypertension is similar to that observed 3 months later (12). Baroreflex dysfunction has been reported in several cardiovascular diseases and in both clinical and experimental hypertension $(4,13)$. In fact, we showed in the same spontaneously hypertensive rat (unpublished data) that there was a good correlation between the baroreflex sensitivity analyzed by the function curve (aortic activity x AP) in anesthetized rats and baroreflex sensitivity analyzed by changes in HR induced by arterial pressure changes in conscious animals. The impairment of aortic afferents was $41 \%$ and the reduction of the reflex responses induced by lowering AP was $46 \%$. The attenuation of reflex bradycardia was higher (79\%), suggesting that changes in other components of the reflex arc may contribute to the impairment. If baroreflex dysfunction is a cause or a consequence of hypertension is still an open question. Aging, diabetes and obesity may induce changes in vascular structure, changing baroreceptor activity. These functional alterations may be related to the hypertensive process (14). On the other hand, vascular mechanoelastic changes are induced by hy- 
pertension, as we have observed in rat models (15-21). Moreover, there is evidence that baroreflex impairment may be secondary to hypertension in humans and experimental animals (22). Baroreflex sensitivity may be changed by various neurohumoral factors such as angiotensin II (Ang II) (23) and vasopressin (24) that can modulate reflex responses by acting on the central nervous system (25) or peripherally (26). Endothelial factors (27), the activity of ion channels (14) and sympathetic activity (23) may also participate in this baroreflex control. Recently we demonstrated that the hypertensive effect of Ang II was dependent on RSNA in highrenin hypertensive rats (28).

\section{Baroreflex control of sympathetic activity in sinoaortic denervation}

Sinoaortic denervation (SAD) in animals has been used to evaluate the role of baroreceptors in modulating AP, HR and RSNA. The cardiovascular alterations produced by SAD have been extensively studied in several species (29-32). The AP level after SAD depends on the extension of denervation, time after surgery and the experimental conditions during pressure measurements. However, a persistent and marked increase in the variability of AP is always observed. Indeed, we showed that AP, HR and RSNA were increased up to $6 \mathrm{~h}$ and returned to control levels 20 days after $\operatorname{SAD}(33,34)$.

Sympathetic hyperactivity has been implicated as the major determinant of increased AP after SAD. Catecholamine measurements, acute and chronic sympathetic blockade, and localized lesioning of the central nervous system have been used to indirectly estimate increased peripheral neurogenic tone (3537). Direct measurements of RSNA were performed by our laboratory first in anesthetized rats $(33,38)$ and more recently in awake animals (34). In this last study we demonstrated a $100 \%$ increase in RSNA within the first $6 \mathrm{~h}$ after SAD, in contrast with the $30 \%$ increase detected after $24 \mathrm{~h}$ (39). Twenty days after SAD, the averaged RSNA was normal (34). These data indicate that the increased sympathetic activity after SAD progressively diminishes to the normal level. The histogram of distribution of RSNA in acute sinoaortic denervated rats was shifted to the upper values (Figure 1), which explains the greater averaged cycle activity. Despite the similar averaged RSNA values in chronic SAD and normotensive rats the pattern of distribution was different (Figure 1 , bottom). There was a higher proportion of silent cycles and consequently a lower 1:1 synchronization between RSNA and cardiac cycles in chronic SAD rats. This alteration in the synchronization of sympathetic activity

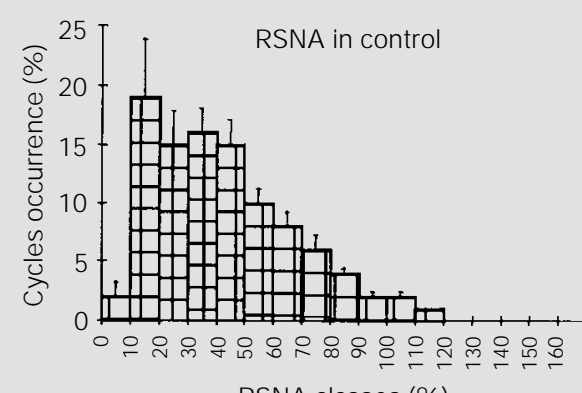
RSNA classes (\%)
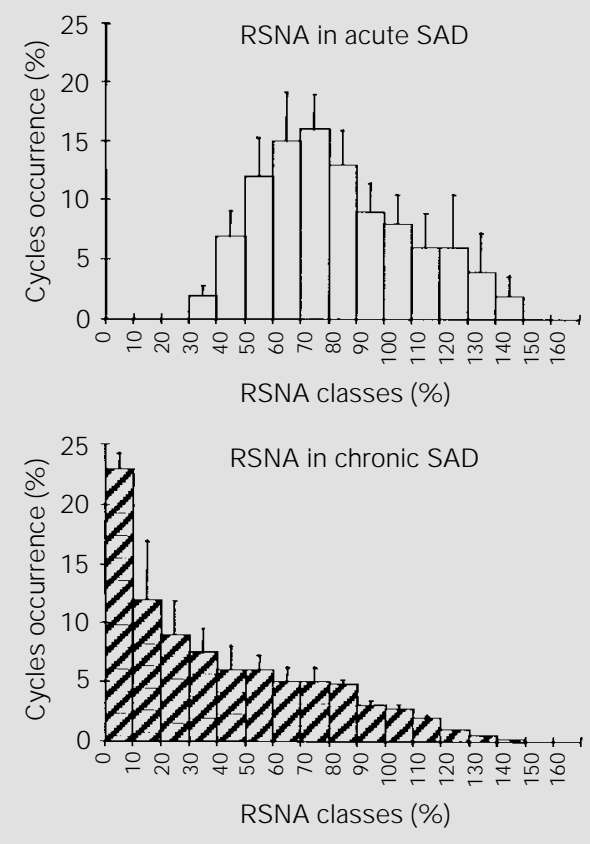

Figure 1 - Bar graphs showing the occurrence of cardiac cycles at each level of normalized renal sympathetic nerve activity (RSNA) in control (top), acute (middle) and chronic sinoaortic denervation (SAD) (bottom). Observe the different proportions of cardiac cycles from 0 to $40 \%$ (from Ref. 34). 
Figure 2 - A, Effects of sinoaortic denervation on the baroreflex control of renal sympathetic activity, during changes in mean arterial pressure induced by sodium nitroprusside (left) and phenylephrine (right). Note the depressed baroreflex responses in rats with acute (SADa) and chronic (SADC) sinoaortic denervation.

B, Scatterplot showing a spontaneous relationship between systolic arterial pressure (SAP) and renal sympathetic nerve activity (RSNA) for each systolic pressure class $(2 \mathrm{mmHg})$ in a control, an acute (SADa) and a chronic (SADC) sinoaortic denervation rat. Observe the larger AP fluctuation in SAD ( $a$ and $c$ ) rats compared to control. could be an important factor to explain the increased lability observed in these animals. The normalization of the averaged RSNA under resting conditions in the chronic phase of SAD is accompanied by normalization of HR (40) and biochemical parameters (37) as well as by normal arterial pressure values (35). However, the impairment of baroreflexes observed in the acute phase (85-92\%) still persisted in chronic SAD (62-72\%) (Figure 2A). Similar depression was found in the baroreflex control of HR, when AP was increased $(74 \%)$ or decreased $(75 \%)$. The relationship between RSNA and AP evalu- ated during spontaneous changes in AP was also attenuated in acute and chronic SAD as compared with control rats (Figure 2B).

In synthesis, sinoaortic denervation produces intense depression of baroreflex regulation of RSNA in both the acute $(6 \mathrm{~h})$ and chronic (20 days) phases. However, only in the acute phase is baroreflex attenuation accompanied by tonic sympathetic overactivity. In the chronic phase of SAD, averaged RSNA, as evaluated over 1000 cardiac cycles, returns to baseline values, but the pattern of discharge is altered, probably contributing to the increased AP variability.

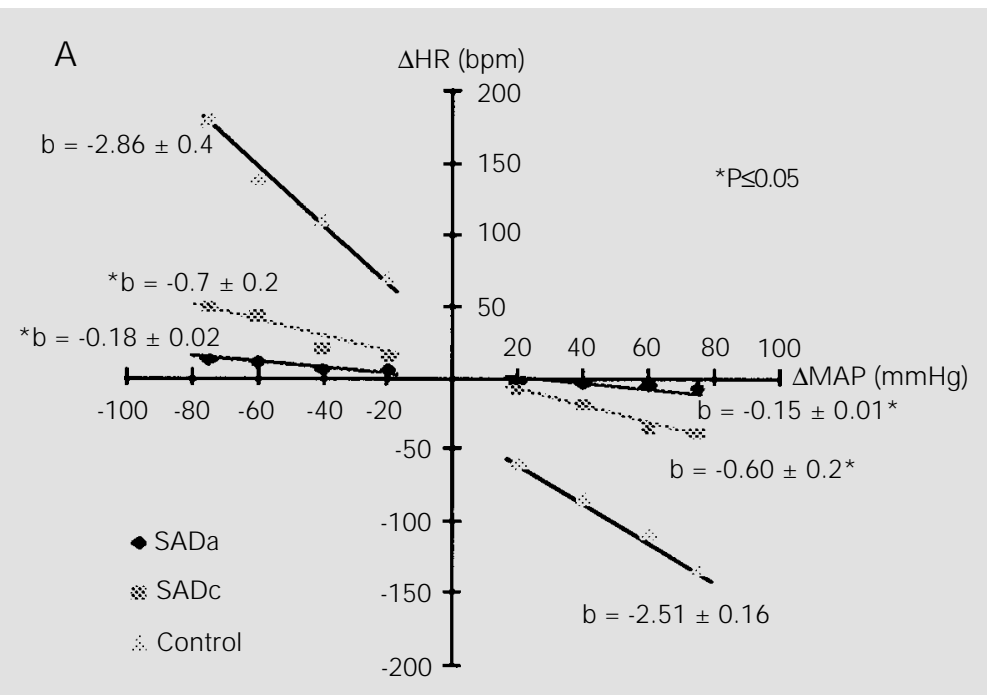

B

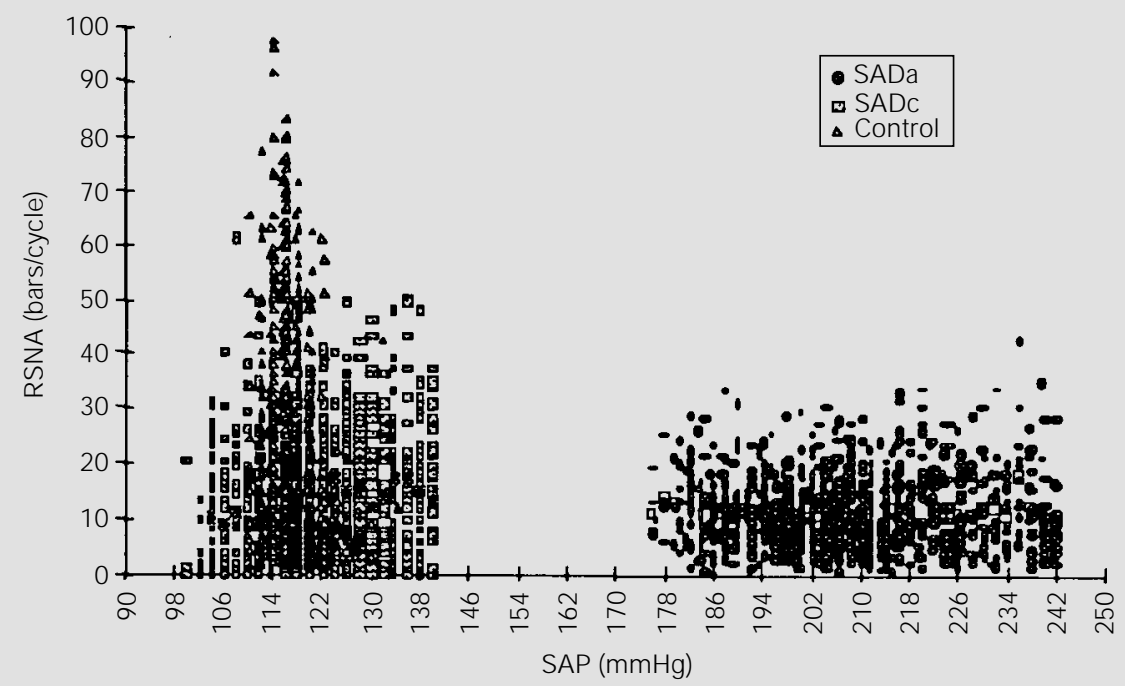




\section{Baroreflex control in high-renin hypertensive rats}

Total aortic ligation between renal arteries is a useful model of high-renin hypertension in rats (41). Compared with normotensive controls we found an AP increase of $54 \%$ in high-renin hypertensive rats (42) $(169 \pm 3$ vs $110 \pm 2 \mathrm{mmHg})$. The overactivity of renin angiotensin system (RAS) was demonstrable by measurements of plasma re- nin activity (PRA) by radioimmunoassay (40 \pm 5 vs $2 \pm 1 \mathrm{ng} \mathrm{Ang} \mathrm{I} \mathrm{ml}{ }^{-1} \mathrm{~h}^{-1}$, in controls) and by the hypotensive response to captopril administration $(-40 \pm 4 v s-9 \pm 5 \mathrm{mmHg}$, in controls). Averaged cycle RSNA evaluated over 1000 cardiac cycles in high-renin hypertensive rats was normal (19 \pm 3 bars/ cycle) when compared with normotensive controls (18 \pm 2 bars/cycle).

The role of the sympathetic nervous system in the pathophysiology of renal hyper-

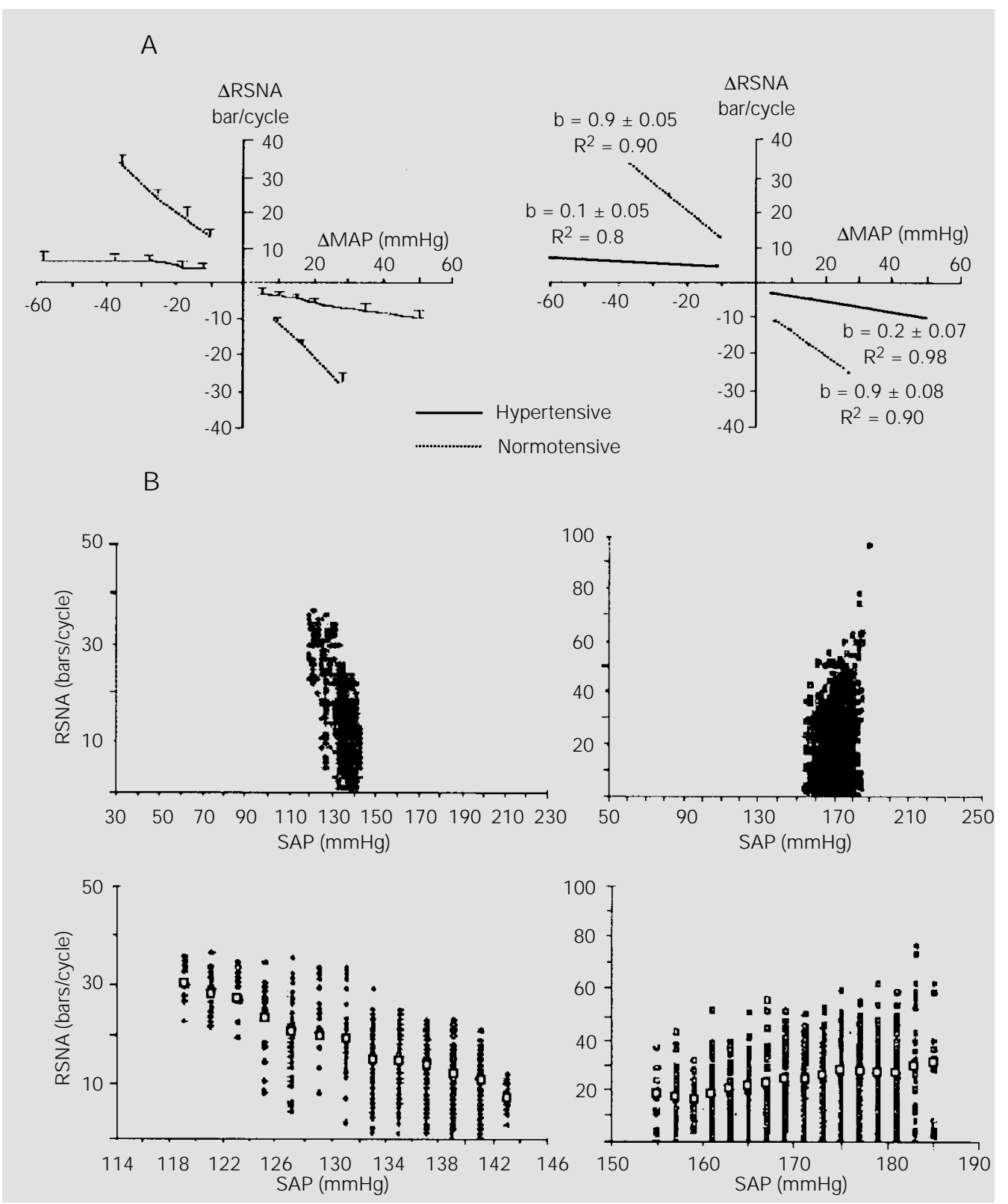

Figure 3 - A, Effects of high-renin hypertension on the sympathoinhibitory and sympathoexcitatory responses to pressor changes induced by vasoactive drugs. On the left, actual values of reflex inhibitory responses (lower right) and reflex excitatory responses (upper left). On the right, regression lines. Solid straight lines: hypertensive rats. Dashed lines: normotensive rats (from Ref. 42). B, Scatterplot showing a spontaneous relationship between systolic arterial pressure (SAP) and renal sympathetic nerve activity (RSNA) obtained from a normal rat (left) and from a high-renin hypertensive rat (right). The open plots in the middle of the figures represent averaged RSNA in each class of systolic pressure. 
tension is still controversial (43). In our laboratory bilateral renal denervation was shown to attenuate the hypertension observed after 10 days of aortic ligation (28). Renal denervation also normalized PRA in these experiments, implicating the renal nerves in the secretion of renin during decreases in perfusion pressure.

Impairment of baroreflex bradycardia by Ang II has been demonstrated in sheep (44), dogs (45), monkeys (46), rabbits (23) and rats (47). Moreover, the pattern of pressure changes during natural sleep in rats, which is a sensitive index of functional integrity of the baroreceptor reflex, is altered by intracerebral Ang II infusion (48) or during hypertension accompanied by overactivity of the RAS (49), thus resembling the changes caused by sinoaortic denervation.

In our laboratory the baroreflex control of HR was demonstrated to be impaired in rats with high-renin renal hypertension of short and long duration, regardless of the severity of hypertension (47). Both reflex bradycardia and tachycardia elicited by phenylephrine and nitroglycerine, respectively, were depressed. In rats with one-kidney, one-clip hypertension, the reflex bradycardia and tachycardia were attenuated by 81 and $77 \%$, respectively. In rats with mild or severe hypertension induced by aortic ligation there was a similar marked inhibition of the reflex bradycardia (90\%) and tachycardia $(62 \%)$.

Although the reduced sensitivity of the baroreflex control of heart rate does not always reflect a similar change in sympathetic outflow to the peripheral circulation, because of the asymmetry of the system (4), in our study the reflex responses of RSNA to loading and unloading of the baroreflex were also attenuated by $70-80 \%$. Indeed, Figure $3 \mathrm{~A}$ shows the actual measured parameters during rises and falls in MAP (42) with an impairment of $73 \%(-0.3 \pm 0.03 v s-1.1 \pm 0.1$ bars $/ \mathrm{mmHg})$ and $79 \%(-0.2 \pm 0.03 v s-0.94 \pm$ $0.12 \mathrm{bars} / \mathrm{mmHg}$ ), respectively. The impairment evaluated by the slope was greater ( 78 and $81 \%$, respectively). The spontaneous correlation between systolic pressure and RSNA is illustrated in Figure 3B. The inverse correlation between systolic pressure and averaged RSNA in each class of systolic pressure (every $2 \mathrm{mmHg}$ variation) was depressed in renal hypertensive rats $(-0.7 \pm$ $0.04 \% / \mathrm{mmHg}, \mathrm{B}$ ) as compared with controls $(-2.32 \pm 0.6 \% / \mathrm{mmHg}, \mathrm{A})$.

In synthesis, high-renin hypertensive rats showed overactivity of the renin angiotensin system and a great depression of the baroreflexes, comparable to the depression observed in chronic sinoaortic denervated rats. However, no increased sympathetic tonic activity or changed pattern of discharge was observed in this hypertensive model.

\section{Concluding remarks}

A marked alteration in the baroreceptor control of sympathetic activity is observed (phasic effect) in both chronic SAD rats and rats with high-renin hypertension. However, the averaged RSNA was normal under resting conditions, suggesting that the impairment of the baroreflex is not always accompanied by increased sympathetic activity (tonic effect) as observed in the acute phase of SAD.

In chronic SAD rats, the pattern of sympathetic discharge was altered and the lability of AP was increased whereas in highrenin hypertensive rats both parameters were normal. These data suggest that alteration in the synchronization of sympathetic discharges, even when the average discharge is normal, can be an important mechanism increasing AP variability. 


\section{References}

1. Krieger EM (1970). Time course of baroreceptor resetting in acute hypertension. American J ournal of Physiology, 218: 486490.

2. Fei $L$, Anderson $M H$, Katritsis $D$, Sneddon J, Statters DJ, Malik M \& Camm AJ (1994). Decreased heart rate variability in survivors of sudden cardiac death not associated with coronary artery disease. British Heart J ournal, 71: 16-21.

3. Farrel TG, Bashir $Y$, Cripps $T$, Malik $M$, Poloniecki J, Bennett ED, Ward DE \& Camm AJ (1991). Risk stratification for arrhythmic events in postinfarction patients based on heart rate variability, ambulatory electrocardiographic variables and the signal-averaged electrocardiogram. J ournal of the American College of Cardiology, 18: 687-697.

4. Mancia G, Grassi G \& Ferrari AU (1997). Reflex control of circulation in experimental and human hypertension. In: Zanchetti A \& Mancia G (Editors), Handbook of Hypertension. Vol. 17: Pathophysiology of Hypertension. Elsevier Science Publishers B.V., Amsterdam, Netherlands, 568601.

5. Head GA (1995). Baroreflexes and cardiovascular regulation in hypertension. J ournal of Cardiovascular Pharmacology, 26 (Suppl 2): S7-S16.

6. Chalmers J P, Kapoor V, Llewellyn-Smith IJ , Minson J B \& Pilowsky PM (1992). Central control of blood pressure. European Heart J ournal, 13 (Suppl a): 2-9.

7. Mancia G \& Mark AL (1983). Arterial baroreflexes in humans. In: Sheperd $J T \&$ Abboud FM (Editors), Handbook of Physiology. Section 2: The Cardiovascular System. American Physiological Society, Bethesda, 755-793.

8. Dampney RAL (1994). Functional organization of central pathways regulating the cardiovascular system. Physiological Reviews, 74: 323-364.

9. Conway J, Boon N, Davies C, Vann J ones J \& Sleight P (1984). Neural and humoral mechanisms in blood pressure variability. J ournal of Hypertension, 2: 203-208.

10. Krieger EM (1989). Arterial baroreceptor resetting in hypertension (The JW MCCubbin Memorial Lecture). Clinical and Experimental Pharmacology and Physiology, 15 (Suppl): 3-17.

11. Mion J r D \& Krieger EM (1988). Blood pressure regulation after deprivation of rapid-eye movement sleep in rats. J ournal of Hypertension, 6 (Suppl): S74-S76.
12. Moreira ED, Ida F, Oliveira VLL \& Krieger EM (1992). Early depression of the baroreceptor sensitivity during onset of hypertension. Hypertension, 19: I-198-I-201.

13. Korner PI (1989). Baroreceptors in hypertension. Clinical and Experimental Pharmacology and Physiology, 15: 45-64.

14. Chapleau MW, Cunningham JT, Sullivan MJ , Wachtel RE \& Abboud FM (1995). Structural versus functional modulation of the arterial baroreflex. Hypertension, 26: 341-347.

15. Michelini LC \& Krieger EM (1981). Mechanoelastic properties of the aorta in chronically hypertensive conscious rats. Hypertension, 3: II-177-II-182.

16. Michelini LC \& Krieger EM (1984). Importance of the time course of aortic diastolic calibre dilation for baroreceptor resetting in acute hypertension. J ournal of Hypertension, 2 (Suppl): S387-S389.

17. Michelini LC \& Krieger EM (1986). Aortic caliber changes during development of hypertension in freely moving rats. American J ournal of Physiology, 250: H662H671.

18. Krieger EM (1987). Aortic diastolic caliber changes as a determinant for complete aortic baroreceptor resetting. Federation Proceedings, 46: 41-45.

19. Xavier-Neto J \& Krieger EM (1995). Viscoelastic behavior of the in situ aortic wall during hemorrhagic hypotension. American J ournal of Physiology, 268 (Heart and Circulatory Physiology, 37): H1773$\mathrm{H} 1780$.

20. Xavier-Neto J , Moreira ED \& Krieger EM (1996). Viscoelastic mechanisms of aortic baroreceptor resetting to hemorrhagic hypotension and to hypertension. American J ournal of Physiology, 271 (Heart and Circulatory Physiology, 40): H1407-H1415.

21. Sumitani M, Cabral AMS, Michelini LC \& Krieger EM (1997). In vivo adaptive responses of the aorta to hypertension and aging. American J ournal of Physiology, 273 (Heart and Circulatory Physiology, 42): $\mathrm{H} 96-\mathrm{H} 103$.

22. Zanchetti A \& Mancia G (1991). Cardiovascular reflexes and hypertension. Hypertension, 18 (Suppl III): 13-21.

23. Guo GB \& Abboud FM (1984). Angiotensin II attenuates baroreflex control of heart rate and sympathetic activity. American J ournal of Physiology, 246 (Heart and Circulatory Physiology, 15): H80-H89.

24. Michelini LC \& Bonagamba LG (1988). Baroreceptor reflex modulation by vaso- pressin microinjected into the nucleus tractus solitarii of conscious rats. Hypertension, 11: 175-179.

25. Campagnole-Santos MJ , Diz DI \& Ferrario CM (1987). Facilitation of the baroreflex by bilateral injections of an angiotensin II antagonist into the nucleus tractus solitarii. Hypertension, 9: 534 (Abstract).

26. Zimmerman BG (1981). Adrenergic facilitation by angiotensin: Does it serve a physiological function? Clinical Science, 60: 343-345.

27. Matsuda T, Bates J N, Lewis SJ , Abboud FM \& Chapleau MW (1995). Modulation of baroreceptor activity by nitric oxide and S-nitrosocysteine. Circulation Research, 76: 426-433.

28. Oliveira VLL, Irigoyen MC, Moreira ED, Strunz C \& Krieger EM (1992). Renal denervation normalizes pressure and baroreceptor reflex in high renin hypertension in conscious rats. Hypertension, 19 (Suppl II): II-17-II-21.

29. Franchini KG \& Krieger EM (1992). Carotid chemoreceptors influence arterial pressure in intact and aortic denervated rats. American J ournal of Physiology, 262 (Regulatory, Integrative and Comparative Physiology, 32): 677-683.

30. Bishop VS, Shade RE, Haywood JR \& Hamm C (1987). Sinoaortic denervation in the nonhuman primate. American J ournal of Physiology, 252 (Regulatory, Integrative and Comparative Physiology, 21): R294-R298.

31. Krieger EM (1964). Neurogenic hypertension in the rat. Circulation Research, 15: 511-521.

32. Ferrario CM, McCubbin J W \& Page IHP (1969). Hemodynamic characteristics of chronic experimental neurogenic hypertension in unanesthetized dogs. Circulation Research, 24: 911-922.

33. Irigoyen $M C$, Cestari IA, Moreira ED, Oshiro MS \& Krieger EM (1988). Measurements of renal sympathetic nerve activity in conscious sinoaortic denervated rats. Brazilian J ournal of Medical and Biological Research, 21: 869-872.

34. Irigoyen MC, Moreira ED, Ida F, Pires M, Cestari IA \& Krieger EM (1995). Changes of renal sympathetic activity in acute and chronic conscious sinoaortic denervated rats. Hypertension, 26 (Part 2): 1111-1116.

35. Franchini KG \& Krieger EM (1994). Neurogenic hypertension in the rat. In: Ganten D \& de J ong W (Editors), Handbook of Hypertension, Experimental and Genetic 
Models of Hypertension. Elsevier Science Publishers B.V., Amsterdam, Netherlands, 482-500.

36. Alexander $\mathrm{N}$, Velasques $\mathrm{MR}$, de Cuir $\mathrm{M} \&$ Maronde RF (1980). Indices of sympathetic activity in the sinoaortic denervated rat. American J ournal of Physiology, 238 (Heart and Circulatory Physiology, 7): H521-H526.

37. Saavedra J M \& Krieger EM (1987). Early increase in adrenomedullary catecholamine syntheses in sinoaortic denervated rats. J ournal of the Autonomic Nervous System, 18: 181-183.

38. Irigoyen MC, Moreira ED, Cestari IA \& Krieger EM (1991) Renal sympathetic nerve activity and arterial pressure relationship after selective denervation of baroreceptor and chemoreceptor. Brazilian J ournal of Medical and Biological Research, 24: 219-222.

39. Barres C, Lewis SJ , J acob HJ \& Brody MJ (1992). Arterial pressure lability and renal sympathetic nerve activity are dissociated in SAD rats. American J ournal of Physiology, 263 (Regulatory, Integrative and Comparative Physiology, 32): R639-R646.
40. Vasques EC \& Krieger EM (1980). Regulatory, integrative and comparative physiology sequence of tachycardia following baroreceptor denervation in the rat. In: Sleight $\mathrm{P}$ (Editor), Arterial Baroreceptors and Hypertension. Oxford University Press, Oxford, England, 413-417.

41. Chatelain RE, Dibello PM \& Ferrario CM (1980). Experimental benign and malignant hypertension with malignant nephrosclerosis. British J ournal of Experimental Pathology, 61: 401-410.

42. Irigoyen MC, Moreira RD, Moreira ED \& Krieger EM (1991). High-renin renal hypertension depresses the baroreflex control of heart rate and sympathetic activity. In: Kunos G \& Ciriello J (Editors), Central Neural Mechanisms in Cardiovascular Regulation. Birkhauser, Boston, 254-264.

43. Brody MJ \& J ohnson AK (1980). Role of the anteroventral third ventricle region in fluid and electrolyte balance, arterial pressure regulation and hypertension. In: Martini L \& Ganong WF (Editors), Frontiers in Neuroendocrinology. Raven Press, Ltd., New York, 249-292.

44. Lee WB, Ismay MJ \& Lumbers ER (1980).
Mechanisms by which angiotensin II affects the heart of conscious sheep. Circulation Research, 47: 286-292.

45. Fukiama K (1973). Central modulation of baroreceptor reflex by angiotensin. J apanese Heart J ournal, 14: 135-139.

46. Wasserstrum N \& Herd J A (1977). Heart rate and oxygen uptake response to angiotensin in the squirrel monkey at $10^{\circ} \mathrm{C}$. American J ournal of Physiology, 233 (Heart and Circulatory Physiology, 1): H10$\mathrm{H} 14$.

47. Moreira ED, Oliveira $M \&$ Krieger EM (1988). Impaired baroreflex control of heart rate in high-renin renal hypertension. J ournal of Hypertension, 6: 619-625.

48. Moreira RD \& Krieger EM (1988). Abnormal blood pressure behaviour produced by intracerebral angiotensin during natural sleep. J ournal of Hypertension, 6 (Suppl 4): S452-S454.

49. Moreira RD \& Krieger EM (1984). Alterations of the pattern of pressure changes during sleep of rats with overactivity of the renin-angiotensin system. Clinical and Experimental Hypertension, 6 (A): 21232126. 